\title{
Edison Carneiro e o samba: reflexões sobre folclore, ciências sociais e preservação cultural
}

\author{
Edison Carneiro and samba: folklore, social sciences \\ and cultural preservation
}

\section{Renata de Sá Gonçalves}

\section{(2) OpenEdition}

\section{Journals}

Edição electrónica

URL: http://journals.openedition.org/aa/438

DOI: $10.4000 /$ aa. 438

ISSN: 2357-738X

\section{Editora}

Programa de Pós-Graduação em Antropologia Social (UnB)

Edição impressa

Data de publição: 1 junho 2013

Paginação: 239-260

ISSN: 0102-4302

\section{Refêrencia eletrónica}

Renata de Sá Gonçalves, «Edison Carneiro e o samba: reflexões sobre folclore, ciências sociais e preservação cultural», Anuário Antropológico [Online], v.38 n.1 | 2013, posto online no dia 01 outubro 2013, consultado o 28 abril 2021. URL: http://journals.openedition.org/aa/438 ; DOI: https://doi.org/ $10.4000 /$ aa.438

\section{(c) $(1)(9)$}

Anuário Antropológico is licensed under a Creative Commons Atribuição-Uso Não-Comercial-Proibição de realização de Obras Derivadas 4.0 International. 
Edison Carneiro e o samba: reflexões sobre folclore, ciências sociais e preservação cultural

No ano de 2012 comemorou-se o centenário do folclorista Edison Carneiro, nascido em Salvador em 1912 e falecido em 1972 no Rio de Janeiro, além dos 50 anos da "Carta do Samba", documento redigido por ele em 1962." Edison Carneiro ficou conhecido nas ciências sociais especialmente por seus livros Candomblés da Bahia (1948) e Antologia do Negro Brasileiro (1950). Escreveu sobre temas diversos, desde os folguedos populares até as religiões afro-brasileiras, e também sobre as escolas de samba do Rio de Janeiro. Foi um dos principais representantes do movimento folclórico na década de 1960. Atuou como pesquisador, militante e como organizador e participante de diversos congressos, principalmente no campo do folclore, mas também de outros, como o segundo Congresso Afro-brasileiro, realizado em Salvador em 1937, ${ }^{1}$ e do Congresso Nacional do Samba, realizado no Rio de Janeiro em 1962, do qual participou ativamente.

O baiano Edison, como destaca a pesquisadora Ana Carolina Nascimento (2010), transitou "de forma mais ou menos tensa e controlada entre muitos universos: os intelectuais, as instituições acadêmicas, o jornalismo, os terreiros de candomblés e os mestres de capoeira, samba e batuque”. Entre Salvador e o Rio de Janeiro, para onde se transferiu em 1939, publicou cerca de 20 livros marcados pelo interesse pela "religião" e pela "cultura popular", e também por suas preocupações políticas como militante do Partido Comunista. Além de importantes livros, ${ }^{2}$ Carneiro publicou, desde os 16 anos de idade, um significativo número de artigos, tanto em jornais de ampla circulação como em revistas especializadas e acadêmicas, além de verbetes para enciclopédias e dicionários.

Dada a amplitude de seus interesses, uma característica especial de Edison merece atenção: "ele não era um intelectual facilmente classificável a partir de uma identidade disciplinar, no entanto, procurou costurar as suas tantas áreas de interesse a partir de uma categoria: "povo'” (Nascimento, 2010:30). Diante desse conjunto, é oportuno destacar a repercussão de alguns dos temas e dos modos de fazer pesquisa empreendidos por Carneiro, lembrando que muitos de 
seus interesses, como as questões raciais e religiosas, os estudos da cultura popular, o papel do pesquisador, a militância e a atuação política, as políticas públicas educacionais e as políticas de preservação cultural, estão na ordem do dia. Tais temas pautam calorosos debates, cujos principais focos de discussão são antigos.

Ao ter em vista a trajetória multifacetada de Carneiro, o principal objetivo deste artigo é trazer à luz os debates sobre uma complexa manifestação popular urbana - o samba, as escolas de samba e a sua preservação, tema que, desde meados do século XX, motiva o interesse dos estudiosos de folclore, das ciências sociais e que serve de reflexão para as políticas culturais.

Neste artigo, importa compreender a posição destacada ocupada por Edison Carneiro, um dos principais expoentes dos estudos de folclore no Brasil, o contexto histórico de seu lugar de atuação política em meio à institucionalização do campo das políticas públicas culturais, e sua singularidade dentro de um grupo diverso de intelectuais. Para tanto, pretende-se focar as escolas de samba como fenômeno histórico e cultural, buscando compreender como elas foram interpretadas no âmbito dos estudos de folclore e das ciências sociais e no bojo da formulação de ações políticas de preservação cultural. Desde a "Carta ao Samba" redigida por Carneiro em 1962, ao Registro do Samba realizado pelo Instituto do Patrimônio Histórico e Artístico Nacional (Iphan), de 2007, que relações podemos estabelecer entre campos de conhecimento e de ação política?

\section{Edison Carneiro e o samba: o folclore e as ciências sociais}

A década de 1950 - tomando como referência a criação da Comissão Nacional de Folclore (1947) e da Campanha de Defesa do Folclore Brasileiro (1958), da qual Carneiro foi diretor entre os anos de 1961 a 1964 - do ponto de vista de iniciativas e realizações, foi o momento do apogeu dos estudos de folclore. Como mostram Vilhena e Cavalcanti (1990), o folclore, a sociologia e a antropologia de então eram interlocutores próximos e o processo de construção de seus respectivos campos de ação pode ser vislumbrado por meio de um jogo de atribuições e auto definições. Os autores destacam que as fronteiras destas áreas se entrecruzavam.

Os folcloristas, voltados para o que julgavam ser as raízes da nossa nacionalidade, deram grande destaque, principalmente entre as décadas de 1940 e 1950, à descrição dos "folguedos populares". O samba, em particular aquele praticado no interior das escolas de samba do Rio de Janeiro, visto em um conjunto mais vasto de tradições, não foi assinalado como uma manifestação especial, mas como uma expressão cultural difícil de se adequar à grande totalidade dos folguedos brasileiros. Um lugar diferenciado e mais próximo da ideia de folclore 
foi reservado ao samba de roda, ao samba de umbigada, ao samba de terreiro, manifestações mais facilmente reconhecidas como folclóricas. Mas como enquadrar o samba urbano, a manifestação das escolas de samba que nascem em meio à própria constituição da cidade?

Representativo da relevância dessa discussão é o debate travado na década de 1960 entre Edison Carneiro e Renato Almeida a respeito da legitimidade de se definirem as escolas de samba como uma manifestação folclórica. Para a compreensão de Almeida, às escolas faltaria "espontaneidade", visto que sua formalização, pautada por regulamentos nos concursos oficiais e por atividades regradas, as distanciava de uma integração orgânica, característica fundamental das manifestações folclóricas. Edison Carneiro, também crítico de determinadas regras e restrições das escolas, como veremos adiante, não as entendia superficialmente como uma potencial expressão folclórica descaracterizada, mas como uma expressão fundamentalmente popular e dinâmica. $\mathrm{O}$ debate entre Carneiro e Almeida é expressivo da busca por um "modelo comunitário de integração" (Vilhena, 1997) presente nas manifestações folclóricas. Mas as escolas de samba poderiam ser entendidas como parte deste modelo?

\section{As escolas de samba do Rio de Janeiro}

Carneiro postulava que sim e demonstrou particular interesse pelas escolas de samba. Embora tenha escrito sobre o samba de umbigada e o samba de roda e os tenha associado a uma grande variedade de tipos unificada pela perspectiva mais integradora dos folguedos populares, chama a atenção a singularidade atribuída pelo autor a um outro tipo de samba, aquele das escolas de samba cariocas.

Sua relação com as escolas não era a de um observador distanciado. Dentre as diversas atuações e homenagens que compõem a carreira de Edison Carneiro, ganham destaque suas condecorações como benemérito da Escola de Samba Portela, sócio honorário das Escolas de Samba Acadêmicos do Salgueiro e Mangueira, presidente de honra da Escola de Samba Cartolinhas de Caxias, do Afoxé Filhos de Gandhi e do Clube Carnavalesco de Frevo Pás Douradas. A partir dessa vivência, como Carneiro compreendeu e defendeu as escolas de samba?

Para apresentar alguns de seus argumentos, foram selecionados os textos de sua autoria sobre as escolas de samba intitulados "Escolas de Samba I" e "Escolas de Samba II", de 1956 e 1957, 3 além de "Proteção e restauro dos folguedos populares", publicado originalmente em 1955. Estes três textos foram republicados no livro $A$ Sabedoria Popular. ${ }^{4}$ Também serão mencionados a "Carta do Samba" ${ }^{5}$ e o manifesto "Em louvor do rancho"(1967), ambos publicados no livro Folguedos Tradicionais. ${ }^{6}$

Nos textos sobre as escolas de samba de 1956 e 1957, elas são descritas por 
Carneiro como "associação que tem por objetivo principal a participação popular como conjunto no carnaval carioca”. Edison leva em conta a integração popular no espaço da cidade, revelando a centralidade do ponto do subúrbio ou do morro - como o Terreiro Grande do Salgueiro - "onde os seus habitantes se reúnem para suavizar com música as durezas da vida” (Carneiro, 1982:89). Ao descrever as suas visitas e andanças com uma pequena equipe, entre 1952 e 1953, "para dar uma visão da incidência de folguedos populares no então Distrito Federal, rastreando-os nas suas origens próximas", Carneiro menciona que "não nos escaparam as escolas de samba, tanto as do morro (da 'colina', como dizia Calça Larga) como as da planície" (Carneiro, 1982:95).

Na descrição das escolas, o autor mescla também o caráter de socialização de elementos distintos - a música popular urbana, o samba de roda trazido da Bahia e os ranchos de Reis. Nesta direção, podemos inferir que Carneiro enfatiza manifestações dos folguedos tradicionais e se abre à apreciação de sua expressão urbana mais moderna, sem hierarquizá-las. Ele destaca que "nas escolas se produz a música não folclórica com influência do rádio e das melodias estrangeiras”, mas reforça também "o retorno à modinha e aos gêneros anteriores" (Carneiro, 2008:79). Nas suas palavras, "as escolas seguem as exigências da hora, mas também realizam o samba-cantado e dançado à maneira antiga, como o partido alto". Carneiro atribui ao samba de roda o passo distintivo do samba. Nas escolas, "o convite à dança não é exatamente a umbigada, mas executa-se uma espécie de reverência, sambando, dizendo no pé, diante da pessoa escolhida”. A escola em marcha é aproximada aos cortejos de Reis, aos ranchos tradicionais. E, assim, essa manifestação, nas palavras de Edison, nascida no Largo do Estácio, espalha-se por vários subúrbios, pelos morros e pela área metropolitana do então Distrito Federal. Ressalta ainda sua expansão pelo país, afirmando que "a escola vai ganhando, paulatinamente, outras capitais, tanto do Norte como do Sul” (Carneiro, 1982:87).

A visão que Edison Carneiro defende das escolas de samba é sempre ambivalente, pois busca dimensionar sua continuidade entre os folguedos populares, mas destaca paralelamente singularidades e críticas ao seu "processo evolutivo". Sobre as disputas, Carneiro menciona "o encontro das escolas na Praça Onze onde resolviam suas divergências, a faca, a pau, a pernada, a pandeiro de tarraxa" (Carneiro, 2008:81). Essas disputas seriam acentuadas pela concessão de prêmios feita por juízes venais e amenizada com a criação da Associação em 1952, tradição disciplinada pelos regulamentos.

O folclorista sublinha o fato de a escola de samba ter vida associativa precária, com exceção dos meses que antecedem o carnaval, o que é relativizado 
quando menciona que as escolas vinham organizando feijoadas, bailes, comemorações, escolhas de rainha, fazendo desse grupo uma sociedade de todo o ano. Destaca que elas ainda estão em pleno processo evolutivo, passando à sociedade civil, aos "grêmios recreativos". Quanto à organização interna, Carneiro valoriza os diversos papéis desempenhados pelos diretores de bateria e de harmonia e pelos compositores. Valoriza as alas com sua unidade orgânica e o "enredo" como a representação de uma ideia ou de um acontecimento em marcha.

O esforço de Carneiro reside nessa tensão permanente em aproximar aspectos que encontram continuidades com alguns folguedos, como o samba de roda, ou os cortejos de Reis e os ranchos tradicionais. Mas não para por aí. Ao mesmo tempo, apresenta um olhar renovado sobre as manifestações populares na cidade e indica problemas, principalmente nos aspectos em que a competição entre as escolas se acirra e na legitimidade daqueles que as julgam, o que fica claro na sua crítica às Comissões Julgadoras.

O julgamento externo contrariava a qualidade atribuída por Carneiro aos cortejos dos ranchos carnavalescos e das escolas. Os primeiros foram grupos carnavalescos que tiveram grande representatividade na primeira metade do século XX, na cidade do Rio de Janeiro. Ficaram conhecidos por seu caráter mais democrático, reunindo grupos sociais diversos vindos dos subúrbios e dos arredores da cidade. Foram os primeiros grupos a se apresentarem no carnaval com compositores e músicas próprias, sendo elogiados por cronistas, literatos e intelectuais por sua boa música, sua dança e as belas apresentações pelas ruas. Contavam com ampla participação popular. Apresentavam um tema específico a cada ano, promovendo a articulação simbólica entre o enredo, a música, as coreografias e a estruturação dos ensaios e bailes - processo ritual que culminava com os préstitos de foliões em grande número ocupando as ruas para festejarem (Gonçalves, 2007). A estrutura do rancho acomodou-se à escola. Na opinião de Carneiro, “o rancho, de base pequeno-burguesa, sustentado pelo comércio, entrava em decadência. A base social da escola, proletária, e mesmo plebeia, e o ritmo vigoroso do samba, que ditou a substituição da orquestra convencional do rancho por instrumentos de percussão, fizeram toda a diferença” (Carneiro, 1982:87).

Diante de seu potencial de articulação popular, os ranchos -manifestação nascida no início do século XX - vinham sofrendo, em meados da década 1950, grandes ameaças de "desaparecimento" devido às dificuldades econômicas para manter suas atividades e os desfiles com a "dignidade merecida". Este parecia ser um problema que Carneiro identificava também entre outros grupos recreativos populares nas cidades, onde as dificuldades de se angariarem recursos para roupas, adereços e manutenção das sedes das associações eram fortemente sentidas, 
visto que os grupos dificilmente contavam com as redes de solidariedade constituídas ou com recursos públicos.

A difícil medida entre o reconhecimento, a marginalização histórica e o florescimento das escolas e também entre o que valorizar, defender ou combater está presente em boa parte dos escritos sobre o tema nos campos de estudos de folclore e das ciências sociais, marcando uma relativa tensão sobre o que seja, como entender e como preservar essa manifestação da cultura popular urbana no Rio de Janeiro.

Já em finais da década de 1960, era emblemático o movimento em torno dos ranchos carnavalescos urbanos, em favor dos quais Edison e outros colegas, jornalistas e amigos do carnaval, assinam o manifesto "Em Louvor do Rancho", datado de 1967, quando essas sociedades já tinham praticamente desaparecido. Entendidos como manifestações folclóricas, promotoras de uma forma de expressão artística e cultural inspirada em elementos já existentes - como os ranchos de Reis com os quais se pareciam - os ranchos carnavalescos urbanos, para Edison Carneiro, indicariam continuidades de elementos tradicionais da cultura popular rural, no sentido organizacional e artístico, e seriam os formadores das bases sociais das escolas de samba (Gonçalves, 2003, 2007). Desse modo, de acordo com a ótica do folclorista, os ranchos e as escolas de samba aproximam-se dos folguedos populares do folclore brasileiro, ao mesmo tempo singularizados por seus contextos social e histórico específicos.

\section{Em defesa do samba: a "Carta do Samba" de 1962}

Nas décadas de 1940 e 1950, o movimento folclórico forneceu o enquadramento predominante de pensamento e de ação sobre um conjunto de fatos culturais atribuídos a segmentos do povo brasileiro, então denominados por folclore. A noção de folclore, defendida por um grande número de pesquisadores, designava o que era considerado produção cultural tradicional, anônima, coletiva, enraizada no homem do povo e em seu território. Esse viés que enfatizava as origens, por meio da busca por modos tradicionais e coletivos, orientava a preservação daqueles fatos folclóricos. Nesse contexto, Carneiro apresentava um modo próprio de estabelecer os parâmetros para as medidas necessárias de preservação. Como bem descreve Vicente Salles na apresentação ao livro Folguedos Tradicionais, "Edison Carneiro se colocou mais ao lado dos portadores de folclore, que a ele se apresentavam sempre desinibidos e solícitos, que ao lado dos teoristas" (Carneiro, 1982:7).

A“Carta do Samba”, redigida por Edison Carneiro, é um documento que sintetiza as recomendações que visavam à preservação do samba. As medidas 
sugeridas foram formuladas por um grupo, do qual Carneiro fez parte, formado por compositores, intérpretes, sambistas, estudiosos e amigos do samba reunidos no I Congresso Nacional do Samba no Rio de Janeiro, em 1962. Nas palavras de Edison,

[...] esta carta que tive a incumbência de redigir representa um esforço por coordenar medidas práticas e de fácil execução para preservar as características tradicionais do samba sem, entretanto, lhe negar ou tirar espontaneidade e perspectivas de progresso. [O Congresso do Samba] valeu por uma tomada de consciência: aceitamos a evolução normal do samba como expressão das alegrias e das tristezas populares; desejamos criar condições para que essa evolução se processe com naturalidade, como reflexo real da nossa vida e dos nossos costumes; mas também reconhecemos os perigos que cercam essa evolução, tentando encontrar modos e maneiras que neutralizá-los (Carneiro, 1982:161).

Para tanto, são indicadas, na Carta, algumas recomendações, como a manutenção das baianas, o abre-alas, a porta-bandeira e o baliza; a defesa da exclusividade da percussão na bateria; e o privilégio das alas. Edison enfatiza que as escolas precisavam urgentemente reintegrar-se ao carnaval carioca, participando ativamente dele e não apenas dos concursos oficiais. Na "Carta do Samba", é recomendado que as escolas abram mão de prêmios e classificações que causariam os atrasos nos desfiles e as rivalidades; que as escolas desistam da apresentação de alegorias em carretas, que as pistas para os desfiles sejam mais largas, que as escolas, em vez de se apresentarem apenas no concurso oficial, desfilem também nos bairros onde tenham sede.

$\mathrm{Na}$ visão de Edison, o sistema de julgamento fragmentado desrespeitava a unidade indivisível da escola. Na competição residia um ponto sensível do lugar paradoxal entre os sentimentos de comunidade e a capacidade de expansão que caracterizam os folguedos e que formam o núcleo social das escolas, de um lado, e as dificuldades encontradas na cidade e a competitividade restritiva dos concursos, de outro. Parece persistir uma preocupação entre o lugar qualificado como mais harmônico e cordial das tradições populares e as disputas individuais e entre grupos próprias da vida nas metrópoles.

As escolas de samba, entendidas por Carneiro como folclóricas e populares, já revelavam nas décadas de 1950 e 1960 um tipo singular de manifestação classificada entre popular e moderna, por sua natureza cordial, integradora, mas também competitiva e agonística. Desse modo, sugiro que tais características colocadas em tensa relação - populares, modernas, folclóricas e urbanas 
- reaparecem nas compreensões sociológicas e antropológicas sobre o carnaval publicadas a partir do final da década de 1970, como veremos adiante. E estarão também presentes nas propostas de ações de preservação do patrimônio cultural, como observaremos na análise de alguns aspectos do processo de Registro do Samba realizado pelo Iphan em 2007.

\section{Nas ciências sociais}

Um corte teórico e ideológico viria a reforçar o processo de estigmatização do folclore - tanto como objeto (as expressões designadas pelo termo) quanto como campo de estudos - ainda na década de 1950, com o crescimento e a institucionalização das ciências sociais no Brasil.

Vilhena nos ajuda a compreender por que o movimento folclórico "responsável pela constituição do campo intelectual no qual nos situamos e agimos hoje" (1997:268) não seguiu como tema prestigiado nas ciências sociais. Os folcloristas, organizados em 1947 na Comissão Nacional de Folclore (CNFL), ${ }^{8}$ expandiram o movimento em comissões estaduais e organizaram importantes congressos. Em 1958, viabilizaram a Campanha de Defesa do Folclore Brasileiro (CDFB), órgão executivo ligado ao Ministério da Educação e Cultura, que teve Edison Carneiro como seu segundo diretor, cargo do qual foi exonerado pelo regime militar em 1964, delimitando a partir de então o fim das crescentes conquistas dos folcloristas. Como indicado por Vilhena, dada a importante atuação de Carneiro na CNFL, o seu afastamento da CDFB representou uma queda significativa nas conquistas de ambas as instituições.

A tese central de Vilhena sustenta que o sucesso do folclore como ação mobilizadora foi o outro lado do seu fracasso como ciência. A institucionalização do folclore se deu a partir da constituição de museus, institutos, órgãos governamentais, e não nas universidades, como também desejavam os folcloristas.

Nas universidades, em finais da década de 1970, as questões urbanas e as festas começam a ganhar mais espaço nas ciências sociais e o tema do carnaval carioca e das escolas de samba passa a ser objeto de pesquisa sociológico e antropológico.

Para se referir àqueles fenômenos folclóricos e populares, uma nova postura com intenção mais científica foi tomada por cientistas sociais e intelectuais. Vale ressaltar que não era de interesse dos cientistas sociais tratar das "continuidades culturais" como entendidas pelos folcloristas, como uma "missão" (Vilhena, 1997), espelhando o próprio universo totalizador estudado, mas sim como objeto de pesquisa social.

Um dos trabalhos inaugurais é do antropólogo Roberto DaMatta que, em 1973, publicou o artigo "O carnaval como rito de passagem" no livro Ensaios de 
Antropologia Estrutural, que seria o ponto de partida para a publicação em 1979 do livro Carnavais, Malandros e Heróis. DaMatta indicou "continuidades" ao seu modo, sintetizando o conflito e a acomodação de dois sistemas de valores no Brasil que se perpetuam. Para ele, o sistema brasileiro é dual: "de um lado, existe o conjunto de relações pessoais estruturais; de outro, há um sistema legal, moderno, individualista, modelado e inspirado na ideologia liberal e burguesa" (DaMatta, 1979:31). Na cultura urbana brasileira, as relações pessoais formam o núcleo da "moralidade" ou "esfera moral", e têm um enorme peso no jogo vivo do sistema, sempre ocupando os espaços que as leis do Estado e da economia não penetram. Desse modo, as relações entre a "modernidade" brasileira - que se faz certamente dentro da égide da ideologia igualitária e individualista - e a sua "moralidade" - que parece hierarquizante, complementar e "holística" - são complexas e tendem a operar num jogo circular.

Em 1978, a socióloga Maria Isaura Pereira de Queiroz publicou alguns artigos, "Evolução do carnaval latino-americano" e "Da definição do carnaval"; em 1984, "Escolas de samba do Rio de Janeiro ou a domesticação da massa urbana"; em 1987, "Carnaval brasileiro: da origem europeia ao símbolo nacional”; e finalmente em 1992, o livro Carnaval brasileiro: o vivido e o mito.

A leitura que Maria Isaura propõe na oposição mito e rito ou vivido e mito explicita a existência de uma outra oposição: a dos sentimentos “essenciais" despertados pela festa carnavalesca e os sentimentos de inquietação diante das transformações. Nas palavras de Maria Isaura, para se ter uma "visão mais profunda da festa”, é indispensável procurar saber quem são os foliões, qual é a sua posição na hierarquia do poder local e da própria festa e, finalmente, o papel que desempenham. "A abordagem sócio-histórica contém certamente uma indicação interpretativa - a crença de que um conjunto urbano, sua configuração, suas transformações exercem influências sobre a configuração e as transformações do carnaval" (Pereira de Queiroz, 1992:217).

Cavalcanti (1994) nos indica outro caminho. Com um olhar renovado quanto a essa forma cultural carnavalesca, a autora aborda as escolas de samba considerando as dimensões horizontal e vertical do desfile e explicita suas tensões, evitando oposições estanques e simplificadoras. O desfile é, assim, apresentado como "uma forma ritual e estética elaborada que expressa um processo vital em fluxo constante". Tal vitalidade, como diz a autora, se deve à capacidade do desfile de absorção e expressão da cidade. Essa forma espetacular e monumental do desfile atual resultaria de uma longa evolução que acompanhou as transformações da cidade do Rio de Janeiro ao longo de grande parte do século XX. Como definiu Cavalcanti (1994), "sua natureza ritual, a um só tempo agonística 
e festiva, permitiu-lhe a absorção e a expansão dos conflitos e relações da cidade em expansão: as camadas populares e as camadas médias, o jogo do bicho e o poder público, a zona norte e a zona sul" (Cavalcanti, 1994:213).

O convívio e o trânsito festivo entre camadas e sujeitos sociais foram também bem explorados na literatura sobre o processo de estabelecimento do samba como gênero musical (Sandroni, 2008) e de consolidação das escolas de samba como principal forma de expressão carnavalesca. A questão mais evidenciada nesses estudos aponta para as especificidades das cidades, das trocas intensas e produtivas entre camadas médias e populares e entre negros e brancos (Vianna, 1995; Moura, 1995). Vianna (1995:20) enfatiza as sociabilidades entre "intelectuais e artistas eruditos de famílias brancas e ricas e músicos negros e pobres” e a existência de indivíduos que agem como mediadores culturais e de espaços sociais onde essas trocas sociais são implementadas (:41).

\section{Políticas de preservação cultural}

No último quartel do século XX, como vimos nos estudos acima indicados, as ciências sociais conquistaram novo vigor teórico e metodológico, promovido pela conexão entre os estudos urbanos e o campo de estudos de rituais, inaugurando criativas abordagens acerca das escolas de samba.

Nas políticas públicas de preservação cultural, principalmente a partir do ano de 2000, verificamos reflexos desse movimento de abertura conceitual e ideológica presente nas ciências sociais. Percebem-se iniciativas de apoio e fomento a expressões de grupos específicos que dificilmente caberiam no universo do folclore, como o funk, ou mesmo as escolas de samba. Aqui nos parece importante retomar a discussão sobre "proteção" tal como elaborada por Carneiro.

Em seu texto de 1955 intitulado "Proteção e restauração dos folguedos populares" (2008), Carneiro alerta para o fato de que, em geral, "admitimos que os folguedos estão desaparecendo ou sendo substituídos por folguedos e diversões não nacionais". O que é contemporizado quando o autor exemplifica com "os milhares de pessoas que se aglomeram para assistir ao desfile das escolas de samba no Distrito Federal, as levas de gente que acompanham maracatus e caboclinhos pelas ruas do Recife" (2008:19-20). Como então tratar os folguedos, essas manifestações da cultura popular?

A expansão e a divulgação são as chaves encontradas por Carneiro. Bastará multiplicar as suas oportunidades de apresentação, na cidade e na zona rural, com aquela "extrema discrição" recomendada pelos peritos da Unesco, deixando aos brincantes liberdade, "muita liberdade” na sua organização (2008:20).

Tal discussão, apresentada na década de 1950, se aproxima de alguns debates 
atuais sobre preservação cultural. Como destaca Carvalho (2010), o avanço das políticas de patrimônio imaterial não pode ser pensado sem se considerar em suas bases portadoras de algumas ideias e orientações semelhantes às que pautaram o movimento folclórico brasileiro, dentre elas, a de preservação.

Desde os princípios das iniciativas de patrimonialização na década de 1920, prevaleceu uma preocupação especial com expressões como as da arte popular, a indígena e a dos negros, as festas populares tradicionais, o artesanato, as canções, as músicas, as danças, identificadas genericamente, naquela época, como folclore. Na década seguinte, a proteção daquilo que fosse "objeto advindo da arte popular, ameríndia, arqueológica” e de expressões do folclore foi parte do anteprojeto elaborado por Mário de Andrade para a criação do Serviço do Patrimônio Histórico e Artístico Nacional - SPHAN, efetivamente instituído em 1937.

Apesar de prever incluir a produção cultural popular em sua concepção inicial, o Iphan voltou-se de modo enfático para a preservação de bens culturais representativos de estilos, padrões e valores de grupos sociais economicamente mais favorecidos e hierarquicamente elevados. O projeto nacional de patrimonialização pautou-se principalmente por frear o desaparecimento ou a deterioração de obras artísticas e monumentos históricos, que então se tornavam passíveis de proteção por meio do tombamento, instrumento este que se aplicou sobretudo a elementos da arte e da arquitetura barroca e católica (Gonçalves, 1995; Fonseca, 1997).

Só a partir das décadas de 1960 e 1970, a concepção de patrimônio iria expandir-se para incluir a preservação de outros bens culturais do povo brasileiro, anteriormente classificados sob a rubrica do folclore (Cavalcanti, 2001).

O processo de amadurecimento e de desenvolvimento dessa orientação para fatos da cultura não material levaria ainda mais de uma década até resultar, só neste início do século XXI, em um programa de governo especificamente dirigido ao patrimônio imaterial. Procedimentos básicos de operacionalização do Programa Nacional de Patrimônio Imaterial - PNPI foram instituídos pelo governo federal em 2000 e, sob a responsabilidade direta do Iphan, foram articulados com várias instâncias da sociedade de modo a implementar a política nacional de referenciamento e valorização de bens culturais em sua dimensão imaterial. A elaboração desse conceito formalizou-se e ganhou expressão jurídica por meio do Decreto 3.551 de 4 de agosto de 2000, que instituiu o Registro de Bens Culturais de Natureza Imaterial como patrimônio cultural brasileiro. Políticas públicas passaram a ser acionadas em função dessa nova compreensão.

Como indica Carvalho (2010), a participação, em alguma medida, dos grupos informais ou organizados da sociedade civil que são os produtores/detentores dos bens culturais referenciais, os inventários e os pedidos de registro de 
patrimônio imaterial constituem processos de diagnóstico e projeção de ações, visando à garantia das condições sociais e objetivas para a continuidade de tais bens. Esses processos vêm se efetivando na forma de planos de salvaguarda, que são projetos e planos de trabalho executados pelos grupos interessados de "produtores e detentores dos bens culturais” em questão, em conjunto com o Iphan.

A autora chama a atenção para o fato de que, embora logicamente articulados, os instrumentos de inventário, registro e salvaguarda não se dispõem necessariamente em ordem cronológica, podendo até prescindir uns dos outros ou intercambiar ações em diferentes etapas. Todos são faces de um mesmo processo de criação e reconhecimento de patrimônios, que varia segundo os contextos em que se opera.

Tais contextos fizeram diferença no próprio modo de se olhar para as manifestações folclóricas e culturais. Como expõe Tamaso (2006), as manifestações culturais, olhadas por folcloristas, são "folclore", "fato folclórico", "manifestação folclórica", enquanto para os antropólogos, elas são "cultura". "Atualmente, a tendência de ambos é de percebê-los como "patrimônio"”. A este respeito, a autora indica que "uma diferença há e não é de objeto, mas sim epistemológica, de como se 'olha' para o objeto" (Tamaso, 2006:7). No caso dos "antropólogos inventariantes", 9 ao participarem do processo de inventário e/ou registro de um bem cultural, devem dar uma especial atenção aos processos de atribuição do valor "patrimônio" em cada caso específico, a fim de observarem proximamente os resultados da inserção desta nova categoria.

É oportuno lembrar que Velho (2006) problematiza essa expansão do patrimônio a partir do relato do tombamento do terreiro de candomblé Casa Branca, em Salvador, Bahia, ${ }^{10}$ acontecido na década de 1980. Pela primeira vez, a tradição afro-brasileira obtinha o reconhecimento oficial do Estado nacional. Ao narrar o processo do qual fez parte como relator membro do Conselho, Velho chama a atenção para os aspectos de divergência e conflito de valores e interesses diferenciados dos atores envolvidos, mostrando que as políticas públicas de patrimônio não podem ser dissociadas da heterogeneidadee da complexidade da vida social.

Cada vez mais incorporada ao repertório dos grupos populares, em especial àqueles organizados, a categoria patrimônio pode ser entendida como polissêmica, tendo determinadas apropriações e compreensões nativas que não correspondem à apropriação jurídica do termo. Seus usos percorrem do plano jurídico ao plano nativo, enunciando concepções, expectativas e estratégias não só distintas nos modos de operar de seus enunciadores, mas também expressando, frequentemente, o confronto entre "usos plurais" da categoria patrimônio (Tamaso, 2007), entendido aqui "o conflito como constitutivo das políticas de preservação" (Tamaso, 2002). 


\section{Em defesa do samba: Registro das matrizes do samba de 2007}

Diante de tais contextos, pautados pela mediação e pelo confronto dos usos da categoria "patrimônio" entre grupos e instâncias de governo, o Iphan aprovou em 2007 o Registro das Matrizes do Samba no Rio de Janeiro: Partido Alto, Samba de Terreiro e Samba-Enredo. O "samba de roda baiano" havia sido registrado pelo Iphan em 2004. Seguindo processos diferenciados, o parecer emitido em 2007 identificava importantes pontos de contato com a tradição baiana. Como exposto no dossiê (2007),

o reconhecimento do samba de roda do Recôncavo Baiano como Patrimônio Imaterial da Humanidade, em 2005, motivou o Centro Cultural Cartola a analisar os variados estilos de samba no Rio de Janeiro, que se originaram nas reuniões musicais em casa de Tia Ciata, no Estácio, nas escolas de samba, nos blocos, nos morros, nas ruas, nos quintais (Centro Cultural Cartola/Iphan, 2007:9).

O processo de pesquisa sobre o samba no Rio de Janeiro, como descrevem Vianna e Sant'Anna (2007) no parecer feito sobre o Registro, levou a um grande debate sobre como defini-lo e circunscrevê-lo naquele contexto.

Ao longo das discussões, entretanto, verificou-se que a expressão "samba carioca” encobria (e, de certa forma, ocultava) expressões tradicionais musicais, coreográficas e poéticas variadas - todas elas relacionadas ao modo como cariocas dos morros e do asfalto, nas primeiras décadas do século XX, interpretaram, transformaram e reinventaram os sambas e outros ritmos rurais e urbanos existentes. Acordou-se, não sem dificuldade e muita discussão, que as expressões contemporâneas mais representativas da tradição do samba no Rio de Janeiro - expressões que podem ser vistas como matrizes das várias outras formas de samba que foram (e continuam sendo) criadas depois - são: o partido alto, o samba de terreiro e o samba-enredo. Como consta do dossiê que compõe este processo, esse recorte contemplou "as três formas de expressão que mais intimamente se relacionam com o cotidiano, com os modos de ser e de viver, com a história e a memória dos sambistas" (Vianna \&Sant'Anna, 2007:4).

Mais recentemente, os diversos mecanismos de preservação da memória do samba foram levantados no Seminário Matrizes do Samba Carioca, realizado pelo Iphan, em agosto de 2012, no Rio de Janeiro. O evento promoveu o encontro e a discussão de como as instâncias de governo, os diversos órgãos 
públicos e as iniciativas privadas poderiam salvaguardar as matrizes do samba. Foram enfatizados os papéis dos centros de memória, das pesquisas e iniciativas pessoais visando aos registros, à doação de acervos e à capacitação de pessoas ligadas às comunidades locais para realizar a tarefa de articulação permanente com os chamados protagonistas do registro. Foram chamados a falar secretários de Cultura do governo de estado, superintendente do Iphan, o presidente da Liga Independente das Escolas de Samba, a coordenadora do Programa de Salvaguarda do Samba do Centro Cultural Cartola e membros do Conselho do Samba formado por compositores e produtores atuantes no meio.

Muitos problemas estavam ligados às transformações do samba, como a lógica atual de composição do júri dos concursos ou a escolha do samba-enredo, temas já apontados nas discussões de Carneiro. A definição do samba-enredo, que privilegia torcidas, e uma grande campanha interna, não necessariamente com a participação da ala orgânica de compositores da escola, foram duramente criticadas. Entretanto, em meio a evidentes tensões que envolvem a crescente comercialização, a dificuldade de lidar com o samba e a chamada economia de mercado, e diante de distintas compreensões da própria ideia de patrimônio, enfatizou-se positivamente, nesse contexto, a fundamental participação dos sujeitos do processo de pesquisa, registro e salvaguarda, pois apenas essa confluência poderia garantir a "continuidade" da memória e da vivência do samba. Entretanto, os agentes envolvidos são muitos e várias são as expectativas geradas pela inserção da ideia de "patrimônio" e pela ascensão das políticas públicas a ela relacionadas.

\section{Edison Carneiro e as continuidades entre expressões culturais: o binômio intervenção e liberdade}

Pensar sobre as continuidades é controverso, já que pode remeter a certo evolucionismo com o qual as abordagens contemporâneas sobre cultura não querem se confundir. A nós parece que as características e as críticas presentes nas reflexões de 50 anos atrás traziam em seu bojo elementos importantes sobre a natureza ambivalente e tensa, carregada de mediações e de conflitos, que estrutura a relação entre as concepções universalista e relativista de cultura. Uma e outra constituem a história da antropologia e podem ser caracterizadas por matrizes, tais como tradição iluminista e tradição romântica; ou paradigmas, como razão prática e simbólica; por identidades disciplinares, como ciência natural da sociedade e antropologia como uma das humanidades; ou ainda, através de objetivos disciplinares: uma ciência em busca de "leis" ou em busca de "significados".

Carneiro não se mantém afiliado a uma tradição ou matriz única, mas propõe uma visão alargada do folguedo popular, como aquela presente no "Manifesto 
aos ranchos" de que "o rancho mantém, galhardamente, uma continuidade emocional muito cara aos brasileiros" (Carneiro, 1982:20), que guardaria, se não uma continuidade em sua estrutura organizacional e artística, mas um prosseguimento de cunho mais profundo: o elo emocional, atualizado pela experiência dos sujeitos na cidade. Logo, sua perspectiva associava os folguedos populares à perpetuação de um elo que os relaciona às tradições autênticas, sem deixar de mencionar a experiência do "povo" nas cidades.

Esta perspectiva estendida da "cultura popular urbana" mais agregadora e aberta proposta pelo folclorista permitia uma compreensão geral da própria ideia de cultura brasileira. Sua visão sobre as escolas de samba revelava, paralelamente, as dificuldades de manutenção dos "folguedos" diante do excesso de imposições como, no caso dos desfiles e cortejos carnavalescos, a promoção de condicionantes econômicos, de grandes investimentos financeiros que marcariam o fim da possibilidade de se cultivar relações consideradas mais espontâneas e cordiais, o que é agravado sobretudo pelas crescentes exigências formais para os licenciamentos e as condições competitivas cada vez mais restritivas. Somam-se ainda outros fatores. Nas palavras de Carneiro, "a liderança das classes, os deslocamentos de população, as dificuldades gerais de vida, tudo parece ter criado uma situação insustentável para os folguedos populares" (2008:21). Entretanto, o autor também indica que havia nas cidades uma grande receptividade para as diversões populares.

Se a população cresceu, a sua composição não mudou. E é certo que o crescimento maior se produziu nas camadas inferiores da população, herdeiras e portadoras do folclore. [...] não será difícil encontrar apoio para os folguedos populares, na forma de dinheiro, materiais, mercadorias, facilidades (2008:22).

Os argumentos de Carneiro são ambivalentes e, por isso mesmo, servem para criticar e para conciliar. O autor, ao defender as escolas, demonstra sua preocupação com as transformações desta manifestação popular, mas ressalta o potencial de integração dos folguedos à experiência social na cidade - nos morros, nas rodas, nas festividades - e para além desses circuitos locais deveriam se expandir, indicando que as apresentações dos grupos poderiam alcançar outras cidades e circuitos diversos de exibição, o que garantiriaa sua continuidade.

Carneiro traz o exemplo da escola de samba Unidos do Salgueiro que, sob o comando do veterano Calça Larga, seguiu de trem a fim de participar do carnaval paulista no ano do centenário da cidade, logo depois de haver desfilado sob 
os aplausos dos cariocas. "E, se agora já não podemos falar em decadência ou desaparecimento dos folguedos populares nestas zonas, não poderemos fazê-lo depois. Estas medidas garantirão a sua permanência e, mais ainda, o seu florescimento" (2008:21).

Sugiro que seus argumentos não devem ser compreendidos como vulneráveis às críticas gerais dos folcloristas que defendiam uma harmonia integradora afastada da vida fragmentada atribuída às cidades, mas servem como reflexões emblemáticas de uma forma de interpretação da cultura popular urbana carioca que sempre lidou com essas tensões pelas quais Carneiro transitava tão bem.

Carneiro se aproxima, sim, da ideia compartilhada pela maioria dos folcloristas de valorização dos "folguedos populares", expressões tradicionais da cultura e imbuídos de uma continuidade do passado para o presente, sem contudo deixar de formular um modo pessoal de compreender tais continuidades porque também afeitas às cidades, à circulação e à expansão dos folguedos, como é o caso das escolas de samba entendidas como uma manifestação dinâmica, que se espraia pela cidade do Rio de Janeiro e por outras cidades do país. Paralelamente, o autor nos indica, no conjunto dos folguedos populares, elementos de continuidade de folguedos distintos - como o cortejo, a roda, o chão, o enredo - que aparecem em diversas expressões da cultura popular através dos tempos, mas que nos apontam também tensões e problemas a serem equacionados no campo da preservação.

A polarização ainda paradigmática para a compreensão das escolas de samba se configura, de um lado, pelo grande campeonato das grandes escolas do grupo especial, pela ampla articulação promovida entre mídia, instâncias de governo, turismo, os patronatos - que “aprisionam” um modelo determinado - e, de outro, pelos mecanismos de preservação de aspectos compreendidos como tradicionais, a exemplo das ações de salvaguarda das matrizes do samba, em que uma atenção especial é dada a certas modalidades de samba - como o samba de terreiro, o partido alto e o samba de enredo, de modo a garantir sua diversidade.

Em 1955, Carneiro apontava que a imprensa e o rádio, se mobilizados, repartições municipais e estaduais e organizações privadas poderiam ajudar na manutenção dos folguedos. Ele também destacava o bem-sucedido associativismo das escolas que desde cedo se organizaram como sociedades civis e, nesta qualidade, "com vantagens e garantias de que desfrutam, consolidaram as suas forças e proliferaram com tal ímpeto que não há bairro carioca que não as possua. União Geral, Federação, Associação Geral que harmonizou toda a família do samba". Finaliza afirmando que "A esta forma geral de associação, que dá unidade, fixidez e responsabilidade ao grupo e lhe amplia a base econômica, 
tornando permanente a contribuição ocasional dos amigos, terão de chegar mais cedo ou mais tarde, por força das circunstâncias, todos os nossos folguedos" (Carneiro, 2008:26).

A intervenção, nos moldes defendidos por Carneiro, deve dar prova de "uma extrema discrição”. A ajuda deve ter caráter excepcional. E, para dar responsabilidade ao grupo, deve-se exigir a prestação de contas de todo o dinheiro ou material que lhe tenha sido entregue. Toda intervenção exige a concessão da mais ampla liberdade, "muita liberdade", aos mestres, aos entendidos, aos animadores, em tudo o que diga respeito ao folguedo em si. (2008:23-24). A síntese do autor presente no "binômio intervenção e liberdade" nos parece bem adequada aos tempos presentes de amplo crescimento das políticas de preservação cultural.

Recebido em 14/09/2012

Aceito em 03/04/2013

Renata de Sá Gonçalves é doutora em antropologia pelo Programa de Pós-graduação em Sociologia e Antropologia da UFRJ (2008). Atualmente é professora do Departamento de Antropologia e do Programa de Pós-graduação em Antropologia da Universidade Federal Fluminense (PPGA/UFF). Tem experiência na área de antropologia urbana e análise simbólica, atuando principalmente com os seguintes temas: cultura popular, festas (carnaval), dança, patrimônio cultural, antropologia dos estudos de folclore. 


\section{Notas}

*. Uma primeira versão deste trabalho foi apresentada no Seminário do Centenário de Edison Carneiro organizado pelo Centro Nacional de Folclore e Cultura Popular (CNFCP) realizado no dia 22 de agosto de 2012 no Rio de Janeiro. Agradeço à professora Maria Laura Cavalcanti, pela leitura e comentários. Agradeço ainda aos participantes do evento, especialmente a Claudia Marcia Ferreira, Elisabeth Costa, Ana Carolina Nascimento e à professora Yvonne Maggie. Agradeço a FAPERJ pelo apoio ao projeto de pesquisa “Transmissão do Conhecimento entre tradições populares. Dinâmicas de reinvenção da cultura" / UFF

1. Como indica Maggie (2012), Edison Carneiro foi um dos organizadores, talvez o mais importante, do segundo Congresso Afro-brasileiro. O primeiro Congresso foi organizado por Gilberto Freyre, em 1934, em Recife. Carneiro foi militante ativo do Partido Comunista Brasileiro e, durante o Estado Novo, perseguido pela polícia, recebeu refúgio no Axé do Opô Afonjá, pela amizade que lhe devotava mãe Aninha (Eugenia Ana dos Santos), talvez a mais notável mãe de santo da Bahia.

2. Dentre suas obras, destacamos as seguintes publicações: Candomblés da Bahia (1948), Antologia do Negro Brasileiro (1950), Dinâmica do Folclore (1950), Linguagem Popular da Bahia (1951), O Negro em Minas Gerais (1956), A Sabedoria Popular (1957), Samba de Umbigada (1961), O Folclore no Brasil (1963) e Ladinos e Crioulos (1964).

3. Publicados originalmente no Diário de Noticias de 25/3/1956 e em Manchete, em 1957, respectivamente.

4. Faremos uso das versões dos textos publicadas na edição de 2008 do livro $A$ Sabedoria Popular editado pela Livraria Martins Fontes, revista e supervisionada por Philon Carneiro, filho de Edison Carneiro. A primeira edição do livro é de 1957 do MEC/INL.

5. Carta proposta ao I Congresso Nacional do Samba, realizado no período de 28 de novembro a 2 de dezembro de 1962 no Rio de Janeiro

6. Faremos uso da $2^{a}$ edição do livro Folguedos Tradicionais (1982) publicada pela Funarte/INF, cuja primeira edição data de 1974. O livro conta com a apresentação de Vicente Salles.

7. O documento foi assinado em 27 de setembro de 1967 por Edison Carneiro, Eneida, Arthalydio Agostinho Luz, Ricardo Cravo Albin, Alberto Rego, Jota Efegê, Ilmar Carvalho e Albino Pinheiro.

8. A Comissão Nacional do Folclore (CNFL) estava ligada ao Instituto Brasileiro de Educação, Ciência e Cultura (IBECC) e foi organizada no Ministério das Relações Exteriores com a finalidade de representar o Brasil na Unesco. As práticas e as políticas estabelecidas pela CNFL foram fundamentais para o desenvolvimento do movimento folclórico (Vilhena, 1997). Carneiro foi presidente da CNFL quando da sua criação e diretor 
da CDFB de 1961 a 1964. Durante o período referido, Carneiro deu apoio para a criação do Museu do Folclore, o que só aconteceria em 1978, quando a Campanha se transformou no Instituto Nacional de Folclore, o atual Centro Nacional de Folclore e Cultura Popular.

9. Categoria criada por Tamaso (2006) e utilizada ao se referir ao antropólogo que executa qualquer função no Inventário Nacional de Referências Culturais, seja pesquisa, trabalho de campo, ou coordenação de inventários.

10. O tombamento foi decidido em maio de 1984, em reunião do Conselho do Iphan, e homologado em 27/06/1986 pelo então ministro da Cultura Celso Monteiro Furtado, nos termos da Lei de número 6292, de 15/12/1975, e para os efeitos do Decreto-lei número 25 , de 30/11/1937. 


\section{Referências bibliográficas}

CARNEIRO, Edison. 1982. “Carta do Samba”; "Em louvor do rancho”. In: Folguedos tradicionais. Rio de Janeiro: Funarte/INF. pp.161-166; 167-168.

CARNEIRO, Edison. 2008. "Proteção e restauração dos folguedos populares"; "Escolas de samba - I"; "Escolas de Samba - II". In: - A Sabedoria Popular. Apresentação de Vicente Salles. São Paulo: Martins Fontes.pp.17-30; 78-83; 84-87.

CARVALHO, Luciana Gonçalves de. 2010. Patrimônio imaterial e cultura popular no Brasil: intercâmbios conceituais e política pública. Seminário UFAM.

CAVALCANTI, Maria Laura \& VILHENA, Luís Rodolfo. 1990. "Traçando fronteiras: Florestan Fernandes e a marginalização dos Estudos de Folclore”. Estudos Históricos, 3(5):75-92.

CAVALCANTI, Maria Laura Viveiros de Castro. 1994. Carnaval carioca: dos bastidores ao desfile. Rio de Janeiro: Funarte/UFRJ.

. 2001. "Cultura e Saber do Povo: uma Perspectiva Antropológica”. Revista Tempo Brasileiro, 147:69-78.

CCC (CENTRO CULTURAL CARTOLA), IPHAN/ DPI. 2007. Dossiê das matrizes do samba no Rio de Janeiro: partido alto, samba de terreiro e samba enredo.

DAMATTA, Roberto. 1979. Carnavais, malandros e heróis: para uma sociologia do dilema brasileiro. Rio de Janeiro: Zahar.

1973. “O carnaval como rito de passagem”. In: . Ensaios de Antropologia Estrutural. Petrópolis: Vozes.

FONSECA, Maria Cecília Londres. 1997. O patrimônio em processo: trajetória da política federal de preservação. Rio de Janeiro: Editora UFRJ.

GONÇALVES, José Reginaldo. 1995. "Em busca da autenticidade: ideologias culturais e concepções de nação no Brasil”. In: - O Brasil na virada do século. Rio de Janeiro: Relume Dumará.

GONÇALVES, Renata de Sá. 2003. “Cronistas, folcloristas e os ranchos carnavalescos: perspectivas sobre a cultura popular”. Revista Estudos Históricos, 32:89-105. 2007. Os ranchos pedem passagem. Rio de Janeiro: Prefeitura do Rio/Secretaria de Cultura.

MAGGIE, Yvonne. 2012. Não há anáguas na África. Edison Carneiro e as linhagens da antropologia do negro no Brasil. Seminário do Centenário de Edison Carneiro, CNFCP. 
MOURA, Roberto. 1995. Tia Ciata e a Pequena África no Rio de Janeiro. Rio de Janeiro: Secretaria Municipal da Cultura, Dep. Geral de Doc. e Inf. Cultural, Divisão de Editoração.

NASCIMENTO, Ana Carolina Carvalho de Almeida. 2010. O sexto sentido do pesquisador: a experiência etnográfica de Edison Carneiro. Dissertação de Mestrado, Programa de Pósgraduação em Sociologia e Antropologia, UFRJ.

PEREIRA DE QUEIROZ, Maria Isaura. 1987. "Carnaval brasileiro: da origem europeia ao símbolo nacional”. Ciência e Cultura, Revista Brasileira para o Progresso da Ciência, 39 (8): 717-729.

. 1978. “Da definição do carnaval”. Cadernos, São Paulo, $1^{\text {a }}$ série, n.11, Centro de Estudos Rurais e Urbanos.

. 1984. "Escolas de samba do Rio de Janeiro ou a domesticação da massa urbana". Ciência e Cultura, São Paulo, pp. 893-909.

1992. Carnaval brasileiro: o vivido e o mito. São Paulo: Brasiliense.

SANDRONI, Carlos. 2008. Feitiço decente: transformações do samba no Rio de Janeiro (19171933). Rio de Janeiro: Jorge Zahar Ed./ UFRJ.

TAMASO, Izabela. 2006. "A expansão do patrimônio: novos olhares sobre velhos objetos, outros desafios...”. Série Antropologia 390, Universidade de Brasília.

. 2002. "Preservação dos patrimônios culturais: direitos antinômicos, situações ambíguas”. Anuário Antropológico 1998:11-50.

. 2007. "Relíquias e patrimônios que o rio Vermelho levou...”. In: Manuel Ferreira Lima Filho; Cornelia Eckert \& Jane Beltrão (orgs.). Antropologia e patrimônio cultural: diálogos e desafios contemporâneos. Blumenau: Nova Letra/ Associação Brasileira de Antropologia.

VELHO, Gilberto. 2006. "Patrimônio, negociação e conflito". Mana, 12 (1):237-248.

VIANNA, Hermano. 1995. O mistério do samba. Rio de Janeiro: Zahar.

VIANNA, Letícia \& SANT’ANNA, Márcia. 2007. Parecer Nº 004/07 - DPI Brasília, 15 de agosto de 2007. Registro das Matrizes do Samba no Rio de Janeiro/RJ: partido alto, samba de terreiro e samba enredo. Disponível em http://portal.iphan.gov.br/portal/baixaFcdAnexo.do?id=1389. Acesso em 15/09/2012.

VILHENA, Luís Rodolfo.1997. Projeto e Missão: o movimento folclórico brasileiro 1947-1964. Rio de Janeiro: Funarte/ FGV. 


\section{Resumo}

O folclorista Edison Carneiro (19121972) foi um dos pesquisadores pioneiros que trouxeram o samba carioca como objeto de reflexão. Escreveu sobre o tema na década de 1950 e defendeu sua preservação na "Carta do Samba", redigida em 1962. Sua atuação nos ajuda a pensar sobre a interlocução estabelecida entre campos do conhecimento - especialmente entre os estudos de folclore e as ciências sociais, e nos permite ainda compreender as iniciativas e os dilemas em torno das ações de preservação do samba como patrimônio cultural.

Palavras-chave: samba, folclore, patrimônio cultural, Edison Carneiro.

\section{Abstract:}

The folklorist Edison Carneiro (19121972) was one of the pioneer researchers in making samba a study object. The author wrote about the topic in the 50s and advocated its preservation in the "Carta do Samba" written in 1962. His performance helps us think about the dialogue established between fields of knowledge - especially among folklore studies and social sciences, and allows us to further understand the initiatives and dilemmas surrounding the preservation of samba as cultural heritage.

Key words: samba, folklore, cultural heritage, Edison Carneiro. 